\title{
Development of a Novel Oven-Furnace
}

\author{
Olaniyi Gladius Babatunde ${ }^{1,2}$, Rufus Sola Fayose ${ }^{1}$, Ayodele Abeeb Daniyan ${ }^{3 *}$, \\ Theresa Chikwuo Ezenwafor ${ }^{2}$, Ebenezer Olubanji Oniya ${ }^{1}$, Nathaniel O. Ajayi ${ }^{1}$, \\ Kunle Michael Oluwasegun ${ }^{3}$, Akintoye Oni Adedeji ${ }^{2}$, Akintunde Ajenifuja ${ }^{2}$, \\ Arinola Gift Akinseloyin², Adelana Razak Adetunji ${ }^{3}$, Samuel Oloruntoba Olugbenga Olusunle ${ }^{2}$
}

\author{
${ }^{1}$ Adekunle Ajasin University, Akungba Akoko, Nigeria \\ ${ }^{2}$ Engineering Materials Development Institute, Akure, Nigeria \\ ${ }^{3}$ Obafemi Awolowo University, Ile-Ife, Nigeria \\ Email: babaniyi2013@gmail.com, daniyanayodele@yahoo.com
}

How to cite this paper: Babatunde, O.G. Fayose, R.S., Daniyan, A.A., Ezenwafor, T.C., Oniya, E.O., Ajayi, N.O., Oluwasegun, K.M., Adedeji, A.O., Ajenifuja, A., Akinseloyin, A.G., Adetunji, A.R. and Olusunle, S.O.O. (2017) Development of a Novel Oven-Furnace. Journal of Minerals and Materials Characterization and Engineering, 5, 62-73. https://doi.org/10.4236/jmmce.2017.52006

Received: October 14, 2016

Accepted: March 14, 2017

Published: March 17, 2017

Copyright $\odot 2017$ by authors and Scientific Research Publishing Inc. This work is licensed under the Creative Commons Attribution International License (CC BY 4.0).

http://creativecommons.org/licenses/by/4.0/

\begin{abstract}
This research work is focused on the design and fabrication of Novel OvenFurnace, using locally sourced materials for the purpose of carrying out drying and thermochemical treatments in accordance to the International Electric Equipment (IEE) regulations. Working drawings were produced, and mild steel sheet was used for the construction of the casing, while other materials for the construction were selected based on functions and properties of the materials, cost considerations and ease of fabrication into component parts. The design closely revealed the parameters and features of the furnace, but the control system was designed to function systematically as Oven and Furnace. Testing was carried out to evaluate the performance of the Oven- Furnace. From the result obtained, it was observed that the Oven-Furnace has fast heating rate which is comparable to rates of conventional brands of furnaces purchased from Germany or Canada. Unlike the ordinary furnaces, this equipment was designed to operate systematically to maintain constant temperature at any set temperature value. The lower cost of design of the Oven- Furnace coupled with its good heat retaining capacity, long estimated life time, uniform heating rate, controlled atmosphere, safety and ease of maintenance justifies the usage.
\end{abstract}

\section{Keywords}

Design, Oven-Furnace, Constant Temperature, Drying,

Thermochemical Treatment, Systematic Function, Control System

\section{Introduction}

Oven and Furnace are different equipment, basically in rated power and temperature, which necessitate their usage at temperatures above room temperature. They both have heating chamber that can be of different sizes depending on the 
type of work to be done. It is an enclosure lagged with refractory and other insulating materials for the purpose of heat conservation in the chamber and prevention of heat loss to the surroundings. The chamber contains the charge and retains heat that should be measurable as well as controlled [1].

Ovens are low temperature built equipment design to operate within a maximum temperature of about $250^{\circ} \mathrm{C}$ and with a tolerance of $\pm 2^{\circ} \mathrm{C}$. It was experimented and established as a fact that its operation should be effective enough to carry out drying process of any material at this low temperature without changing the structure and chemical composition of the material. Drying which is a process of removing the moisture content of a substance is carried out at low temperature values, though the equipment that is used for the process in most cases maintain the set temperature at a constant value (isothermal) for a period of time depending on the type of material and the extent of drying.

On the other hand, furnaces are high temperature built equipment (having a very high tolerance at low temperature), that is furnace cannot be operated to maintain a constant temperature at low temperature values even at $500^{\circ} \mathrm{C}$. So, furnaces are not used for drying but for heating [2]. Therefore, numerous processes usually rely on the utilization of furnaces to heat and cool the material after some predefined thermal routine cycle [3] [4] [5].

Heating process is carried out to alter the surface chemistry of the material towards a desired purpose. In most cases, these structures are not achieved without maintaining the heating process at a constant temperature for a period of time, for example carburization process of metals. It is however worrisome that oven and furnace are not used by most of our small and medium scale metallurgical factories and most universities/research institute because of the cost of procurement from overseas and the cost of maintaining the few available ones. Thus, the numerous advantages derivable from them are not being harnessed as a result of the cost factor [6].

The Oven-Furnace on the other hand is a much more reliable to utilize because of its versatility, high performance yield, combining the functions of oven and furnace. The Oven-Furnace can be utilized for drying and for conventional heat treatment process such as; carburizing, nitriding and cyaniding [7]. For instance, the equipment will perform excellently for production of nano filters which involves drying and about two stages of heating, at $105^{\circ} \mathrm{C}$ before heating at $500^{\circ} \mathrm{C}$ and $850^{\circ} \mathrm{C}$ because of its ability to maintain constant temperature at any set temperature value. It is equally useful for preheating, isothermal quenching, austempering etc. Apart from its versatile process usefulness, it also has the advantage of giving uniform heating of the material and controlled atmosphere [8]. These advantages make the use of Oven-Furnace an indispensable facility in drying and heat treatment operations. The huge advantages of the Oven-Furnace make it alluring for an attempt to be made to design the equipment using locally sourced materials. This research work is an attempt to produce a low cost functional and efficient electric fired Oven-Furnace with little 
skill of maintenance that is in accordance to International Electric Equipment (IEE) Regulations [9], which includes basic standard parameters for the design and construction of oven and furnace such as, the safety/control system, the electrotechnicals, the insulating system and the casing fabrication.

\subsection{Aim}

The aim of the work is to develop a systematic Oven-Furnace as a unit capable of drying and heating synthesized materials (such as silica), heat treating ferrous, non-ferrous and production of nano filters.

\subsection{Motivation}

The main motivation for the work is to be able to carry out production of certain materials such as nano filters in a single equipment, which is not possible with either oven or furnace but both. And the fact that constant temperature with low tolerance is not achievable at low temperatures especially with the use of furnace.

\section{Material Selection and Methodology}

\subsection{Materials}

Mild steel sheet was used for the construction of the Oven-Furnace casing while other materials for the construction were based on function and properties of the materials, cost consideration and ease of fabrication into component parts.

The materials that were utilized for the construction of the Oven- Furnace are; $2 \mathrm{~mm}$ thick mild steel sheet, $25.4 \mathrm{~mm}$ by $50.8 \mathrm{~mm}$ rectangular pipe, $10 \mathrm{~mm}$ thick steel rod, refractory cement, silica sand, sodium silicate (binder), $\mathrm{CO}_{2}$ gas, plywood, wood, nails, fibre glass, paint, insulating tape, body filler, adhesive, plug, switch, wire, contactor, thermocouple, temperature controller.

Tools: Marking out tools (pencils, marker, scribers, dividers), measuring tools (steel rule, tri square, vener calliper), harmer, hand file, anvil, bending machine, power hacksaw, welding machine, angle grinder, digital multi-meter, optical pyrometer.

\section{Materials Selection}

\section{1) Steel sheet}

The steel sheet selected is mild steel. It was selected for the fabrication of the Oven-Furnace casing ahead of Aluminium and stainless steel because of its light weight, excellent formability, availability, and low cost.

\section{2) Oven-furnace lining materials}

Refractory cement and silica sand were selected alongside with sodium silicate which is a good binder when mixed in a good proportion as lining material for the Oven-Furnace ahead of silica brick because of its easy casting and baking, low cost, high refractoriness and very low thermal conductivity. Other components and parts selected for the design were influenced by cost, availability, efficiency and reliability. 


\subsection{Design}

\section{Design Principles}

The principles contained in this work are based on the logical necessity of furnace parameters as recommended by the IEE regulations (British Standard BS 7671) [10]. It is aimed at meeting the desired standard as expected for an electrical heated furnace. The Oven-Furnace consists essentially of a container made of metal. It comprises both the internal and external casing. The internal casing serves as support for the refractory box. It must be rigidly constructed to accommodate the weight of the bricks, while the external casing houses the entire furnace system, with the charging door and control panel box containing the electrotechnicals attached to it. With the external casing, the temperature around the walls of the casing falls so that one can freely touch the body without being exposed to danger of high temperature or burning, dimensions of these parts mention are stated in the discursion below. The mode of heat transfer to the work piece is by convection. The design philosophy was to fabricate an Oven- Furnace that will work efficiently at an affordable cost of production.

Thus the following design considerations were taken.

Power consumption (electric) require to operate the equipment should be at a minimum. Experimental test observation showed that an average of 17.0 litres of fuel (Diesel) was consumed by a 100 kva generator in 60 minutes. This gives an estimated 17.0 litres/hr consumption rate.

The component parts such as circuit breaker, contactor, heating element, thermocouple etc should be easily replaceable in case of damage or failure; and.

The design should be simple for easy construction, operation, maintenance, and safety of operator must be guaranteed.

\subsection{Constructing the Oven-Furnace}

\subsubsection{Construction of the Casing}

Flat sheet of mild steel of $2 \mathrm{~mm}$ thickness was selected for its ductility, strength and toughness that support its formability. $50.8 \mathrm{~mm}$ by $50.8 \mathrm{~mm}$ angle iron and $25.4 \mathrm{~mm}$ by $50.8 \mathrm{~mm}$ rectangular pipe were also selected.

Procedure: $50.8 \mathrm{~mm}$ by $50.8 \mathrm{~mm}$ angle iron and $25.4 \mathrm{~mm}$ by $50.8 \mathrm{~mm}$ rectangular pipe cut to size were first joined by welding machine to form framework to which the external casing will rest and the floor to which the refractory bricks will sit. For the external casing, measuring tools were used to measure two of 625 $\mathrm{mm}$ by $500 \mathrm{~mm}$ plates for the sides of the Oven-Furnace. Another two of 520 $\mathrm{mm}$ by $500 \mathrm{~mm}$ were also cut, using cutting disc for the top and base parts of the casing. Also two $500 \mathrm{~mm}$ by $495 \mathrm{~mm}$ sheet were cut and used for the back and front covering of the casing. The edges of the sheets were welded to the frame using welding machine. A $10 \mathrm{~mm}$ hole was made on top of the cover through the internal casing using hand drilling machine with $10 \mathrm{~mm}$ drilling bit for the exit of gases from the Oven-Furnace.

\subsubsection{Construction of the Charging Door}

The construction of the charging door was designed to open and close sideways 
direction. The essence of the design is to reduce the charging and unloading time so that heat lost during its operation is reduced. Two holes were drilled on it for bolts and nuts to hold the refractory brick.

Materials: Mild steel sheet of $3 \mathrm{~mm}$ thickness

Tools and equipment used; Marking out tools, measuring tools, welding machine, carbon electrodes, hand files, anvil.

Procedure: Measuring tools were used to mark out two of $300 \mathrm{~mm}$ by $290 \mathrm{~mm}$ and cutting disc was used to cut the sheet to dimension. The charging door is a double wall sandwich with fibre glass to prevent the door from direct heating from the refractory attached to it.

\subsubsection{Construction of the Control Panel Box}

The $2 \mathrm{~mm}$ mild steel sheet used was marked out, cut, folded and welded to form a box with dimension ( 455 by 400 by 110 ) $\mathrm{mm}$ but open at the top. The two sides were perforated to allow ventilation because of the electronic components it housed. The positions for the temperature controller, main switch, micro switch, circuit breaker, ceramic connector and hole for the passage of connecting cables were measure out and cut using chisel and hand drilling machine. The contactor was fixed inside the box with the help of bolt and nut. The control panel was positioned at the lower part of the casing with the help of angle iron for easy fixing and removal.

\subsection{Lining of the Oven-Furnace}

The lining of the Oven-Furnace was carried out in three stages which are:

Mixing: This involved mixing of dry silica sand and refractory cement in a ratio of 2:1 with sodium silicate (binder) in a predetermined proportion. The mixing was carried out manually.

Casting: The resultant mix was poured into a wooden mould that has eight number of $10 \mathrm{~mm}$ iron rods that runs through the length of the mould for the side refractories. After pouring, it was properly rammed with stick and gassed with $\mathrm{CO}_{2}$ to allow easy and fast setting, more so, to prevent cracks when the iron rods and wooden mould are removed. The removal of these rods created holes for the housing of the heating element thereby shielding the work-piece from direct heat.

Drying and baking: This require the refractory to dry in air for two weeks. After air drying, the refractory was gradually dry in a kiln at a range between $100^{\circ} \mathrm{C}$ and $300^{\circ} \mathrm{C}$ for two hours in seven days in order to remove the moisture content of the refractory and hence improve the strength of the refractory lining. The dried refractories were also placed in a kiln and baked at a temperature of $1500^{\circ} \mathrm{C}$ for one hour in five days. The refractories at the door and at the back were also cast in the same way but are without holes as they do not house the heating element.

\subsection{Assembling}

After the completion of the fabrication processes, that is the casing which com- 
prises the metal frame, outer casing, the inner casing, the charging door and the control panel box as shown in Figure 3. The parts of the steel sheet utilized for the design were seam-welded to give good finishing. The spraying of the casing was done on highly prepared surface, and an auto base paint was used to prevent the casing from corrosion and to give aesthetic finish.

It also involved the following:

Position of the Oven-Furnace casing, setting the refractory bricks housing the heating elements and sealing the openings at the edges where the refractories meet with refractory materials so that the chamber will be airtight and aid the Oven-Furnace atmospheric control (the picture of the arrangement of the refractory bricks after baking is shown in Figure 1), the refractory covering the back and the refractory at the charging door, fixing the gap between the refractory lining and the inner casing with fibre glass to prevent heat loss to the surrounding, the arrangement was air tight thereby giving the Oven-Furnace a good heat retaining capacity and controlled atmosphere, fixing the thermocouple inside the Oven-Furnace through the outer casing, inner casing and the refractory at the back such that it is not in proximity to the refractory housing the heating element preventing direct heating but uniform heating rate and finally introduction of control panel box (earth) containing the electrotechnicals through angle iron for easy fixing and removal at the lower part of the body, also for safety of personnel and components which are made up of thermosetting materials, and for ease of maintenance.

\section{The Electrotechnicals}

\section{Main switch and micro switch}

Description; The main switch and micro switch are parts of the electrotechnicals. The main switch control the power source input as it allows electric power to flow into the circuit when switch on and prevent the inflow when switch off. The micro switch is controlled by the lever attached to the charging door. After charging when the door is closed and the main switch on, the lever presses the micro switch on the control panel box, thereby completing the circuit. The Figure 2 shows the position of the switches in the circuit.

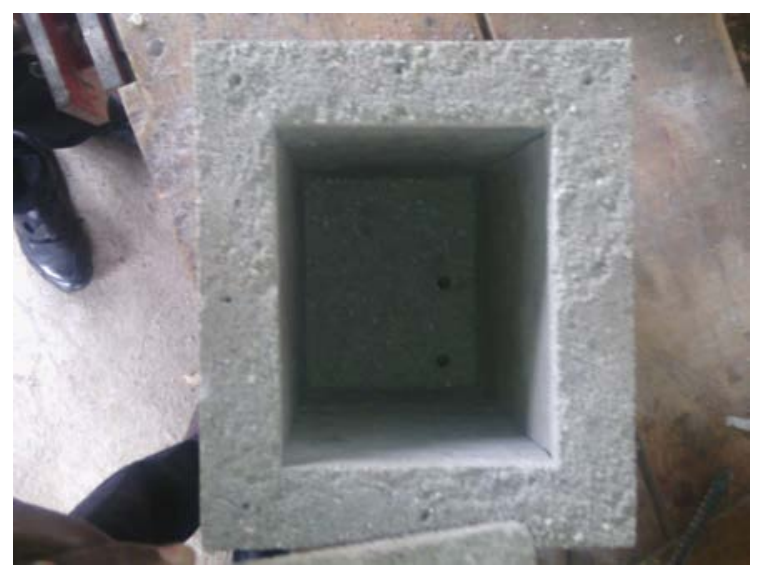

Figure 1. Picture of the setting of the refractory bricks after baking. 


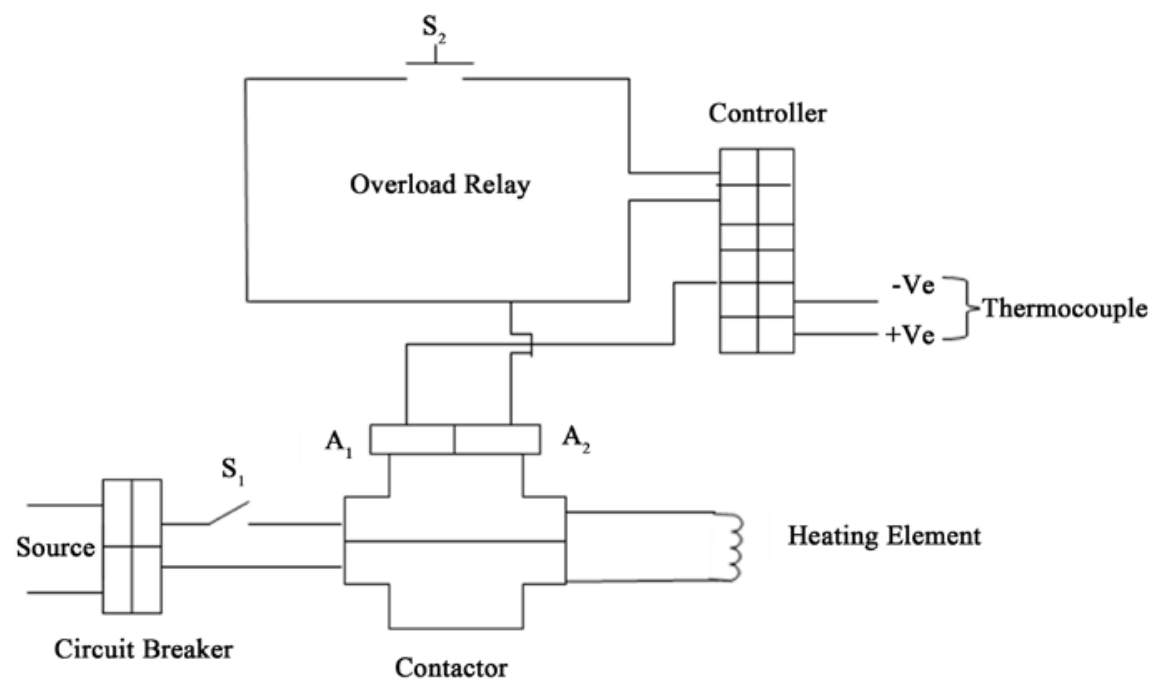

Figure 2. Circuit diagram of the control system.

\section{Temperature controller}

Description: A digital type temperature controller that can be read at a distance, with precise reading and that can read temperature above $1500^{\circ} \mathrm{C}$ was provided since the expected maximum temperature is $1300^{\circ} \mathrm{C}$. Other parts of the electrotechnicals involved are contactor, circuit breaker, ceramic connector and heat resistance cables. They are all positioned on the ( 455 by 400 by 110) $\mathrm{mm}$ metal sheet box just below the charging door where the temperature is very minimal and fusing or damage is prevented during operation. All parts are assembled together as shown in Figure 3. The assembly was made possible with the use of arc welding, boring and screwing with the use of appropriate tools. While electrical parts are also joined and insulated with tape to prevent shocks or discontinuity in the circuit.

\subsection{Testing}

The Oven-Furnace after installation was first tested as oven when it was used to dry synthetic silica at a temperature of $200^{\circ} \mathrm{C}$. The tolerance at this low temperature value was $\pm 2^{\circ} \mathrm{C}$. This is not achievable with ordinary furnace because it is high temperature built. It was further tested as furnace by setting the temperature at $1000^{\circ} \mathrm{C}$ (tolerance of $\pm 5^{\circ} \mathrm{C}$ ). Different values were taken at $100^{\circ} \mathrm{C}$ interval. After test running, the equipment was calibrated using optical pyrometer. The performance and working efficiency of the Oven-Furnace was evaluated by determining the heating rate and ability to maintain constant temperature.

\section{Performance Evaluation}

The performance of the Oven-Furnace was evaluated by using its functionality (Temperature sensing, Power consumption rate, and heating rate), cost analysis, maintainability, estimated life time, and carburizing efficiency as basis for assessing the efficiency of the equipment. 


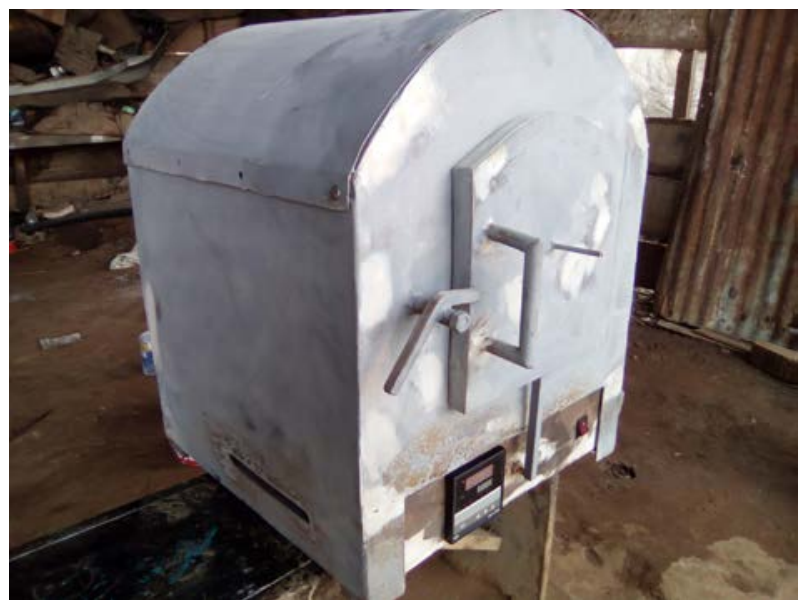

Figure 3. Picture of the oven-furnace under construction.

\subsection{Functionality of the Oven-Furnace}

\section{1) Effectiveness of Temperature sensor}

The thermocouple tip was positioned in the chamber through the outer casing and the refractory covering the chamber at the back. The refractory has no heating element in it. The thermocouple was not position to be in proximity to the refractories housing the heating element inside the chamber to prevent direct heating. So there is uniform temperature inside the chamber. The thermocouple direct signal (heat) to the temperature controller which is a digital type for easy and accurate reading; also there is regular temperature check using an external probe and optical pyrometer to calibrate the temperature controller reading thereby guaranteeing effective temperature reading (Figure 4).

\section{2) Heating rate}

The heating rate of the Oven-Furnace was equally evaluated as it serves as a measure of the time taken to attain the desired temperature and the duration of the treatment. The Oven-Furnace was tested to $850^{\circ} \mathrm{C}$ and a time of 60 minutes was taken to attain the temperature. This test was repeated for five consecutive times and the same average time of 60 minutes was taken to attain the temperature. Temperature readings as against the time of operation were recorded with an heating rate of $14.17^{\circ} \mathrm{C} / \mathrm{min}$ shown in the graph below. .This heating rate is quite high in comparison to $7.08^{\circ} \mathrm{C} / \mathrm{min}$ of the $30 / 60$ capacity salt bath furnace designed in Germany by Degussa [11]. The furnace heats to a carburizing temperature of $850^{\circ} \mathrm{C}$ in 120 minutes. Also imported muffle furnaces like that, which was designed by the Park Thermal Equipment Company in Canada, which takes averagely 150 minutes to heat up to a carburizing temperature of $870^{\circ} \mathrm{C}$ that is a heating rate of $5.8^{\circ} \mathrm{C} / \mathrm{min}$ [8]. Thus the Oven-Furnace design can be said to be very efficient in service in comparison to existing furnaces of different makes within and outside the country. Equally critical in the performance evaluation is its sensitivity and ability to maintain a constant temperature during isothermal treatment. This was evaluated by studying temperature changes when the Oven-Furnace utilized for carburization treatment of the mild steel test samples at $870^{\circ} \mathrm{C}$. It was discovered that at the set temperature $\left(870^{\circ} \mathrm{C}\right)$, the Oven- 


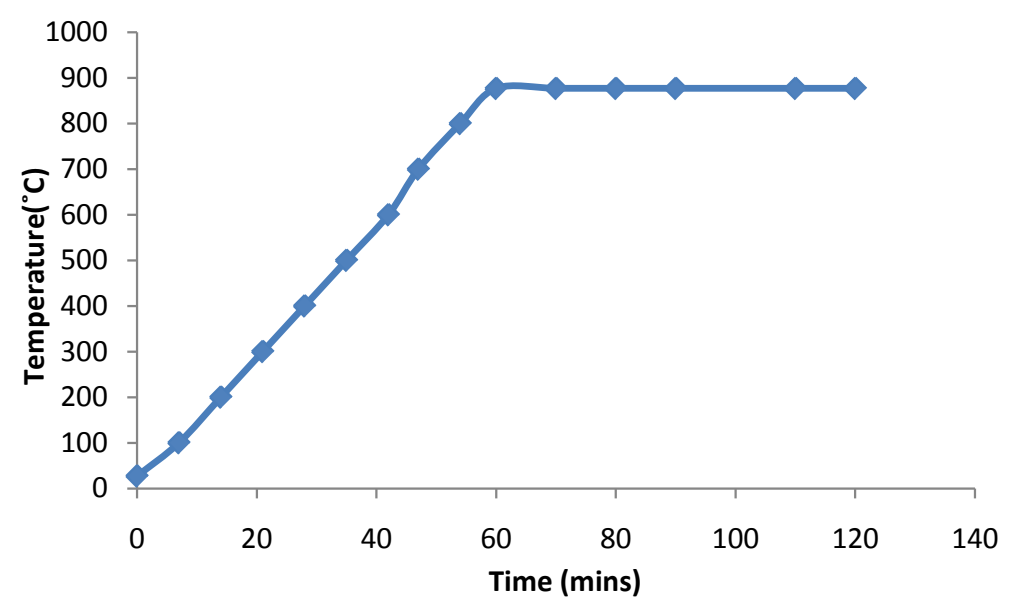

Figure 4. The graph of heat treatment indicating heating and soaking. Heating rate = $(\mathrm{OQ}-\mathrm{OP} / \mathrm{OC})^{\circ} \mathrm{C} / \mathrm{min}=(877-27 / 60)^{\circ} \mathrm{C} / \mathrm{min}=(850 / 60)^{\circ} \mathrm{C} / \mathrm{min}=14.17^{\circ} \mathrm{C}$.

Furnace maintained a steady temperature of $870^{\circ} \mathrm{C}$ with tolerance of $\pm 5^{\circ} \mathrm{C}$. The Oven-Furnace lining also shows its effectiveness by preventing high rate of heat transfer from the heating chamber to the furnace surroundings.

\section{3) Fuel consumption rate}

The fuel consumption rate is very important while determining whether the equipment is efficient, especially from the running cost effectiveness point of view in particular when on generator. The fuel consumption rate of the generator was evaluated by determining when the equipment attains the set temperature. Experimental test observations show that an average of 17.0 litres of fuel (Diesel) was consumed in 60 minutes. This gives an estimated 17.0 litres/hour consumption rate. This rate of fuel consumption reduces with longer holding time during the thermochemical treatment.

\subsection{Maintainability of the Oven-Furnace}

The service life and efficiency of the equipment can be enhanced by simple maintenance, and by following safety measures which are outline in section 3.4. An external probe (thermocouple connected to digital multimeter) is used at regular intervals, at least after 5 heats to calibrate and confirm the accuracy of the temperature readings of the temperature controller.

\subsection{Carburizing Efficiency}

Table 1 bellow displayed the results obtained after hardness tests (using micro hardness tester) were carried out on test samples to evaluate the performance of the Oven-Furnace. It was observed that the case and core hardness value is higher when acarburizing temperature of $870^{\circ} \mathrm{C}$ was utilized in comparison with the selection of a carburizing temperature of $800^{\circ} \mathrm{C}$. Also the case and core hardness increases with the use of longer carburizing soaking time. The trend observed is consistent with the results reported by [12] who performed similar treatment using conventional furnaces. Since the developed Oven-Furnace yields similar results under the same test conditions as the conventional furnaces, then 
Table 1. The variation of case and core hardness at different temperatures and soaking time with the use of the oven-furnace.

\begin{tabular}{cccc}
\hline Sample & Treatment & Case Hardness (HRA) & Core Hardness (HRA) \\
\hline A & $870^{\circ} \mathrm{C}$ for 60 mins.oil quench & 57.2 & 52 \\
B & $870^{\circ} \mathrm{C}$ for 120 mins.oil quench & 60.4 & 54.2 \\
C & $800^{\circ} \mathrm{C}$ for 60 mins.oil quench & 54 & 51 \\
D & $800^{\circ} \mathrm{C}$ for 120 mins.oil quench & 56 & 51.5 \\
E & Untreated & 50 & 50 \\
\hline
\end{tabular}

it could be said to be reliable for use for thermochemical treatment of steel materials.

\subsection{Safety}

The Oven-Furnace should always be positioned in a well ventilated area which reduces the risk of inhaling salt fumes such as cyanide fumes and it will also help to reduce the heat radiation from the equipment to its environment [13]. Thus any other operations can comfortably be carried out near the Oven-Furnace environs without the fear of heat radiation. Also the Oven-Furnace is non-flammable, has very low volatility and it does not pollute the environment. The temperature of the Oven-Furnace was accurately maintained since the thermocouple is well positioned in the Oven-Furnace heating chamber. More so, the temperature controller was well calibrated.

\subsection{Aesthetics}

The casing of the Oven-Furnace is fabricated using the necessary tools such as roller folding machine to ensure smooth surface. The parts of the steel sheets used for the design were seam welded to give good finishing. The spraying of the casing was done on a highly prepared surface using body filler and sand paper; and an auto base paint was used to beautify and also to protect the casing from corrosion.

\subsection{Operation Procedure}

The operation procedures of the Oven-Furnace involve placing the material to be heated in the heating chamber after which the door should be closed. Thereafter switch on the main switch, the microswitch is operated by the lever attached to the charging door and complete the circuit when the charging door is closed. Then, bottons of the digital controller are pressed appropriately to set the controller to the desired heat treatment temperature. After attaining the set temperature and hold (when necessary) for a reasonable time, the equipment is switch off before removing the sample.

\subsection{Possible Heat Treatment Application}

The life time of furnace depends on how many heat treatment cycles the refrac- 
tory lining can withstand [13], while its capacity in terms of temperature depends on the melting point of the heating element used. Based on the heating element (Nichrome wire melting point $1375^{\circ} \mathrm{C}$ ) and thermocouple (maximum temperature $1370^{\circ} \mathrm{C}$ ) used, the Oven-Furnace can be said to be $1300^{\circ} \mathrm{C}$ capacity because it was taken to a temperature of $1250^{\circ} \mathrm{C}$ while test running and calibrating with an optical pyrometer of $3000^{\circ} \mathrm{C}$ capacity. Therefore the equipment is guaranteed to handle heat treatment up to $1200^{\circ} \mathrm{C}$. Considering some certain heat treatment operations and their relative process temperature, it will be possible to carry out any drying process and the following heat treatment processes; production of some nano-materials like nano filters, production of ceramic thin films, annealing, normalizing, tempering, quenching, hardening processes, formation and deformation of polymers.

\section{Conclusion}

The design, construction and performance evaluation of electric powered OvenFurnace using locally available materials was carried out in this research work. Though it was designed for controlled drying and heating of materials and metals within the temperature range of $0^{\circ} \mathrm{C}$ to $1300^{\circ} \mathrm{C}$ but can equally be adapted for use in other drying and heating operations of the same temperature range, such as production of materials. The result obtained during testing of the Oven-Furnace shows that the equipment has a heating rate of $14.17^{\circ} \mathrm{C} / \mathrm{min}$ which is comparable to the rates of conventional brands of muffle furnaces and oven which are imported. The lower cost of design of the Oven-Furnace coupled with its good heat retaining capacity, uniform heating rate, controlled atmosphere, safety, ease of operation and maintenance justifies the usage.

\section{References}

[1] Rajan, T.V., Sharma, C.P. and Sharma, A. (1988) Heat Treatment Principle and Techniques. Pergamon Press, Oxford, 201-220.

[2] Azargohar, R. (2009) Production of Activated Carbon and Its Catalytic Application for Oxidation of Hydrogen Sulphide. Ph.D. Thesis, Department of Chemical Engineering, University of Saskatchewan, Saskatoon.

[3] Howes, H. (2007) New Approaches to Steel Heat Treatment. 2nd Edition, Publisher, Location, Butterworth, Germany.

[4] Netsushori, K. (1998) Various Heat Treatment Technology, Trends and Prospects of Heat Treatment in 21st Century. 3rd Edition, 201-233.

[5] Hasanuzzaman, M., Saidur, R. and Rahim, N.A. (2010) Analysis of Energy and Exergy of an Annealing Furnace. Proceeding of the 2010 International Conference on Mechanical and Aerospace Engineering (ICMAE 2010), Kuala Lumpur, 26-28 November 2010, 60-64.

[6] Alaneme, K.K. and Olanrewaju, S.O. (2010) Design of a Diesel Fired Heat-Treatment Furnace. Journal of Minerals \& Materials Characterization \& Engineering, 9 , 581-591. https://doi.org/10.4236/jmmce.2010.97041

[7] Yutaka (2000) Salt Bath Heat Treatment, Trends and Prospects of Heat Treatment in 21st Century. 3rd Edition, 140-147. 
[8] Reid, B. (2006) Pack Thermal Industrial Heating; Solution to Salt Bath Furnaces, Ontario, Canada.

[9] International Electric Equipment (IEE) Regulation (1994) European Economic Area, Oporto.

[10] Locke, D. (2008) Guide to the Wiring Regulations: 17th Edition IEE Wiring Regulations (BS 7671: 2008). John Wiley \& Sons, Ltd., Hoboken.

[11] Degussa (2006) Degussa Fuel-Fired Furnace Handbook. Degussa Salt Bath Company, Germany.

[12] Gupta, J. (2009). Mechanical and Wear Properties of Carburized Mild Steel Samples. M. Tech Thesis, National Institute of Technology, Rourkela, 1-58.

[13] Alaneme, K.K., Olanrewaju, S.O. and Bodunrin, M.O. (2011) Development and Performance Evaluation of a Salt Bath Furnace. International Journal of Mechanical and Materials Engineering (IJMME), 6, 67-74.

Submit or recommend next manuscript to SCIRP and we will provide best service for you:

Accepting pre-submission inquiries through Email, Facebook, LinkedIn, Twitter, etc. A wide selection of journals (inclusive of 9 subjects, more than 200 journals) Providing 24-hour high-quality service

User-friendly online submission system Fair and swift peer-review system Efficient typesetting and proofreading procedure Display of the result of downloads and visits, as well as the number of cited articles Maximum dissemination of your research work

Submit your manuscript at: http://papersubmission.scirp.org/ Or contact jmmce@scirp.org 